\title{
Exploring the Future of Development Learning: The Open Learning Campus.
}

\author{
https://doi.org/10.3991/ijac.v10i2.7470 \\ Sheila Jagannathan \\ Open Learning Campus, The World Bank Group, Washington DC, USA \\ sjagannathan@worldbank . org
}

\begin{abstract}
The Open Learning Campus is changing the landscape for development learning around the world. By incorporating innovative ways of sharing knowledge across development professionals, partners, and clients, OLC provides learners a real opportunity to seamlessly and efficiently learn and grow, thereby increasing motivation and retention. This study explores the Open Learning Campus, its knowledge sharing tools and systems, as well as its impact within and outside the World Bank Group.
\end{abstract}

Keywords-development learning, learning platforms, learning systems, knowledge sharing, E-learning

\section{About the Open Learning Campus}

\subsection{Introduction}

The development challenges that affect thousands of poor, marginalized, and underserved populations across the globe are complex varying from gender inequality, climate change, sanitation to governance, financial inclusion and urbanization among others. Filling knowledge gaps in these challenge areas through learning initiatives could lead to improved communications and collaborative solutions, especially if that learning is accessible at any time for any one in a position to affect real change.

It was in this context that the World Bank Group in 2014 received a mandate from its president, Jim Yong Kim, to serve as a "Solutions Bank," with the goal of connecting staff, clients, partners, and the general public to knowledge and solutions to meet the Bank's twin goals of ending poverty and building shared prosperity. The mandate empha sized democratizing and advancing learning, so that every citizen has a chance to change and grow in a fluctuating global economic landscape.

The World Bank Group initiated a major reorganization process to improve the knowledge flow between regions and sectors and facilitate knowledge exchange with- 


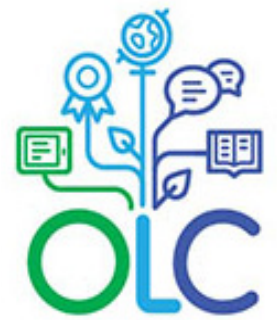

\section{Open Learning Campus ACCELERATING SOLUTIONS THROUGH LEARNING}

in the Bank, and between the Bank and its stakeholders. This reorganization created an opportunity to take advantage of the new technologies that are transforming the learning landscape globally, making it easier to have knowledge available just-in-time and sized to our needs, rather than staying within the four walls of face-to-face learning.

Thus, in 2016, the Open Learning Campus was established as a single destination, go-to place for online development learning that simplifies and consolidates the Bank's learning programs and provides an integrated, joint learning environment. Currently, the Open Learning Campus is a program of the Global Operations Knowledge Management division of the World Bank Group.

Learning is key to solving development challenges, and to meeting the World Bank Group's twin goals of ending poverty and building shared prosperity. Whether it is food security or Ebola outbreaks, development progress is often challenged by multiple interdependent factors. Mitigating these factors requires change that can be harnessed through continuous learning.

By providing dynamic learning opportunities where diverse audiences can learn at their own pace and access the knowledge they need, the Open Learning Campus (OLC) equips individuals with the knowledge and capabilities to tackle the toughest development challenges.

Inspired by the success and credibility of proven approaches to online learning, the OLC is a learning ecosystem that is open, interactive and networked. It leverages the vast knowledge of the WBG and its partners and converts it into actionable learning for effective development. The OLC helps scale development learning by offering a comprehensive learning curricula with wider access and an enhanced learner experience. In the OLC, development lessons continuously captured throughout the world are available in versatile formats, at your fingertips, from bite-sized lessons to fulllength courses to peer-to-peer conversations.

\subsection{Objectives and Approach}

The Open Learning Campus aims to provide a platform where Bank staff and other individuals have access to the same cutting-edge and real-world knowledge on leadership, sectoral areas, and operations, in order to learn how to co-create solutions to development challenges.

The Open Learning Campus is intended to be the go-to place for continuous development learning that will build the leadership and technical capabilities of all devel- 
opment stakeholders-partners, practitioners, policy makers, staff, and the public. More than a website, an LMS or a corporate training site, the Open Learning Campus is a learning ecosystem that is open, interactive and networked. This symbiotic arrangement benefits learners by providing them with the skills and knowledge they need in policymaking and the latest tools, information and strategies in development. This learning hub also connect users to each other through communities of practice, face to face learning and interactive offerings such as the latest development-oriented gamification offerings.

The Open Learning Campus delivers learning that is credible and rooted in knowhow. It curates existing content developed by experts within the World Bank Group and its partners across other development organizations. It also works with operational teams across the Bank to distill their practical knowledge and experience into bitesized learning, in-depth courses, and communities of practice. Learning products align with the challenges and solution areas identified by clients, in line with the changing global environment.

For example, the facilitated course, Debt Management Performance Assessment (DeMPA) offers real-world case studies in comprehensive debt management through application of the DeMPA tool. In a self-paced course on estimating greenhouse gas emissions in land use projects, learners use the Bank's in-the-field experience to learn how to apply a practical carbon balance tool for their own climate-smart agriculture initiatives.

The data within OLC is highly portable and accessible, especially with the development of its mobile App to accommodate individual learners as global users increasingly become highly mobile. At the highest level, the Open Learning Campus's approach is:

- Focused on solutions: Systematically capturing and mobilizing practical insights and solutions on "what works" globally, informed by local context, and shared in accessible ways.

- Interactive and participatory: Moving away from lectures to learner-centric activities, such as role-play, peer reviews, scenario analysis, storytelling, simulations, live webcasts, webinars, social networks and collaborative projects.

- Multi-channel: Leveraging diverse channels, such as face-to-face, virtual classrooms, social networks and mobile technologies to strengthen interactivity, collaboration and problem-solving.

- Experiential: Using real-world problems to help learners apply and integrate development concepts. Examples include cases, problem sets, guided inquiry and reflection, learning labs and simulations.

- Game-infused: Using gaming techniques, such as storytelling, incentives and competition via points, badges and levels, to increase motivation and engagement.

- Expert facilitation: Accessing international experts to provide structure, guide discussions, answer questions, build a community and widen the learning network.

- Learning from peers: Creating a space for collaborative learning, enabling practitioners to ask questions, share tacit knowledge and benefit from the experiences of their peers facing similar challenges. 
- Dynamic: Promoting a learning environment with the latest ideas, topics, learning methods and conversations that are improved through iterative feedback loops. Knowledge captured throughout the world is continuously being shared and learned at any time and at any pace.

The Open Learning Campus (OLC) provides access to an unparalleled repository of global development learning across all sectors and regions [1]. It builds on recent efforts to translate both World Bank Group and global knowledge into accessible learning. In the past four years, the World Bank Group has produced more than 450 digital learning activities, reaching more than 250,000 learners in 190 countries through the e-Institute, which piloted e-learning for development practitioners with great success. Within two years of its operations, the OLC platform has received close to 4 million website page view since its launch in January 2016.

The OLC is designed to deliver learning that is credible and rooted in practical know-how. It features global best practices shared by influential voices in development. Its learning products align with the challenges and solutions areas identified by the World Bank Group's clients through a globally accessible library of learning.

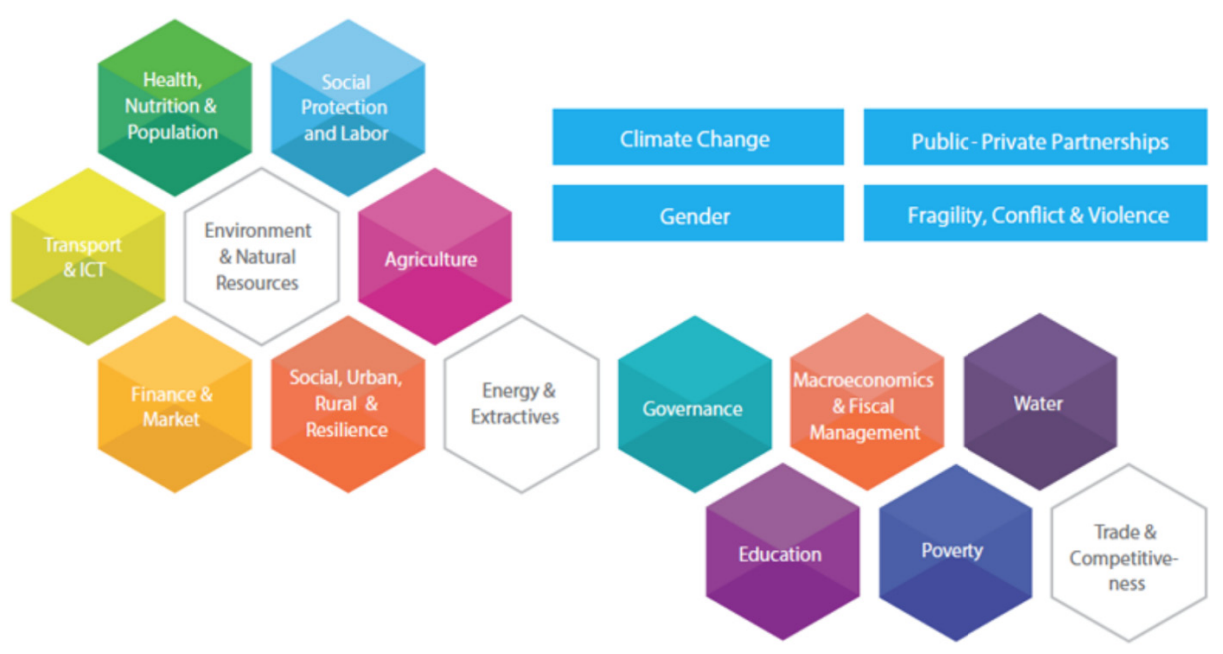

Fig. 1. OLC Learning Products Sectors.

Currently, World Bank Group learning products are delivered through regional and country partner institutions. For example, the Open Learning Campus formed a partnership with the Chinese Academy of Governance to translate and localize a global learning program on sustainable urban land use planning. Now, thousands of mid- to senior-level Chinese civil servants participate in the program annually.

Over time, aggregating and curating content and using feedback from partner institutions is helping to raise the overall quality and effectiveness of the Open Learning Campus, while rendering learning design and delivery more cost-effective. In addi- 
tion, the Open Learning Campus engages external partners to explore both in-kind and financial support to scale up learning.

\subsection{The Open Learning Campus Structure}

The OLC's content is delivered through three schools:

- In WB Talks, learners explore nuggets of knowledge through talks, podcasts, videos, briefs, and games that provide a just-in-time overview of materials targeted to their specific interests.

- In WB Academy, learners unpack deep learning related to development challenges and solutions through virtually facilitated or self-directed e-courses, Massive Open Online Courses, and materials from face-to-face courses.

- In WB Connect, learners connect with experts and peers around the world to share knowledge and work together to find crowd-sourced and sourced solutions to development challenges.

\section{The Open Learning Campus: Positioning in E-Learning}

\subsection{The Open Learning Campus Support System}

The Open Learning Campus is modeled after successful learning platforms and maintains strategic partnerships with some of the biggest knowledge and online learning providers such as Coursera, edX, Harvard Department of Population Medicine, Emerson College, Erasmus University Rotterdam, Partnership for Market Readiness, elearnAfrica and the University of Edinburgh.

To maintain the high quality and relevance of its content, the OLC also partners with national and regional centers of development excellence around the world such as the Global Poverty Reduction and Inclusive Growth Portal, Urban SDG Knowledge Platform, KPESIC LAC, Bio Carbon Fund, China Distance Development Learning Network, Korea Development Institute and many more.

The Open Learning Campus positions itself as a unique and transformative development-oriented initiative of The World Bank Group (WBG) that allows development partners, policy makers, specialists, staff and a broader public to learn together, applying just-in-time learning to key development challenges, and obtaining practical solutions. By learning from the educational sector and tailoring its content to development challenges, the OLC is the go-to place for development learning. In just two years, this has been evidenced by the level of engagement received from its stakeholders, that culminated to the 2016 Gold Best Advance in Creating an Extended Enterprise Learning Program Award from Brandon Hall and the 2017 International E-Learning Awards, Business Division.

To support its vision and goals, the Open Learning Campus benefitted from a strong internal support from the World Bank Group and its president Jim Yong Kim, 


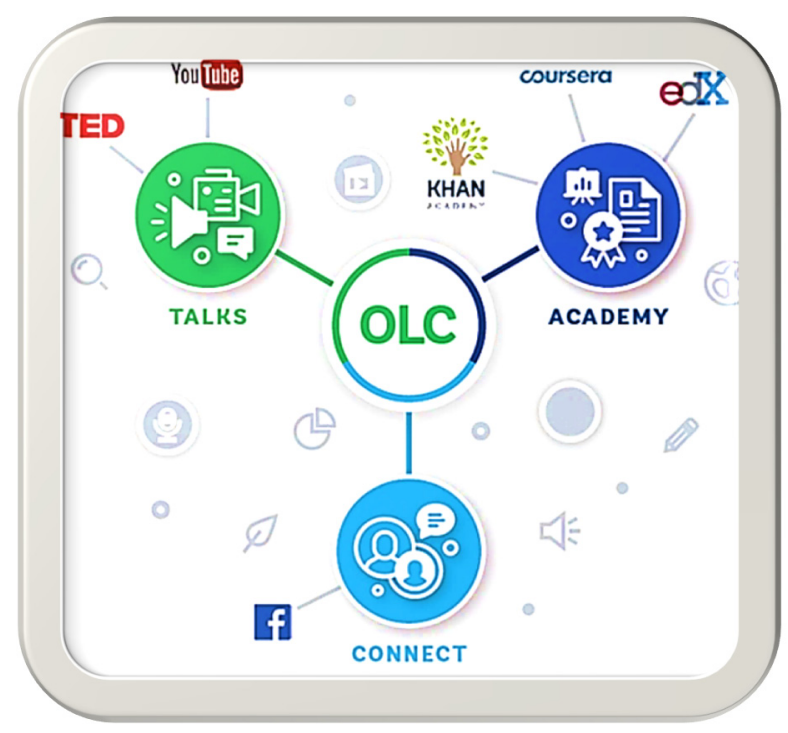

as well as high level donors including Austria Ministry of Finance, Denmark Ministry of Foreign Affairs, Finland Ministry for Foreign Affairs, France Ministry of Foreign Affairs and International Development, Government of Canada through the Canadian International Development Agency, Korean Ministry of Strategy and Finance, Luxembourg Ministry of Finance, Slovak Republic Ministry of Finance and United Kingdom Department for International Development.

The OLC's development partners include LINGOs, African Development Bank, Asian Development Bank, Climate Investment Funds, Food and Agriculture Organization of the United Nations, GovLoop, Greenhouse Gas Management Institute, InterAmerican Development Bank, IMF, Learn4Dev, UN CC:Learn, UNDP, UNFCCC, USAID and many more [1].

\subsection{Using Innovative Solutions to Improve the Scale and Impact of Learning}

As a global development institution, the World Bank Group (WBG) produces expert knowledge and great materials on development issues. Yet, the impact of this knowledge can only be fully realized when transformed into learning for everyonefor development partners, practitioners, policy makers, our staff and for the public. Of the approximately $\$ 700$ Million spent annually on knowledge products of various types, barely $2 \%$ of knowledge on development issues is currently translated into structured learning that a Mongolian, Bangladeshi or Nigerian policy maker can relate to as actionable content [2].

The bulk of this development knowledge is not easily accessible or digestible, and does not translate into practical learning for country clients who need to design and implement reforms. A challenge faced not only by the World Bank Group but almost most organizations is the ability to produce practical learning from tacit knowledge. Tacit knowledge is defined as the unwritten, unspoken, and hidden vast knowledge 
held by an individual based on his insights, experiences, observation and internalized information. Tacit knowledge is acquired largely through association with other people, and requires joint or shared activities to be imparted from one individual to another.

Through its third school, WB Connect, enables learners to engage with others through peer and expert learning to find crowd-sourced solutions to development challenges. Knowing the value and importance of tacit knowledge, the Open Learning Campus, through its Communities of Practice and Face to Face learning encourages peer to peer learning by creating a space for collaborative learning, enabling networking and the free flow of tacit information from the experiences of connected individuals. Using a range of innovative tools, from social media to mobile texts, knowledge exchange can be promoted between WBG staff, clients, partners and global citizens.

OLC's strong focus on peer learning has been evidenced by the level of engagement on its platform. A recent MOOC (Massive Online Open Course) had approximately 10,000 conversations in three weeks. This by-product of our courses and tools helps in the co-creation of solutions for some of the toughest development problems. OLC's philosophy remains that online learning to be interesting and effective it has to be creative, in terms of grabbing learner attention, providing interactivity with experts, peers and content and creating opportunities for dialogue and discussions that capture tacit knowledge and feed this back into the learning loop.

The OLC is also able to address development learning gaps by scaling innovative digital and online learning to meet its learners where they are. Engaging individuals to share their knowledge and learning on development challenges and solutions with the wider community is a core value of the WBG's Open Learning Campus. In this context, observations have shown that a story is often a powerful learning tool [2]. This idea is not a new one; in fact, stories have been a universal form of knowledge transfer for over 100,000 years as a way of connecting people and creating a common perspective on social, economic, political and cultural issues that they care about.

Research led by storyteller Kendall Haven [3] has demonstrated that audiences become fully engaged in new information when they perceive the content to be personally relevant to themselves, through a personal viewpoint through which they begin 'owning' the story. For example, the wildly popular African TV drama Shuga is watched by over 500 million and has woven into the story the ideas of promoting safer sex and dismantling prejudices against HIV/AIDs. In the World Bank Open Learning Campus, story structures are similarly used to engage audiences so that the information, including expert interviews, short talks, webinars, podcasts etc. can successfully and positively influence them.

Through the Open Learning Campus' WBx portal, the power of storytelling makes the available information personally relevant and compelling. An example is the African youth series under the title "Africa's Youth in Action" that was widely popular among African young leaders. OLC's use of storytelling includes innovative ways to use multimedia, ranging from documentary style stories to animations, simulations, and in the future, immersive learning through virtual reality. 
Virtual reality refers to technology that generates realistic images, sounds, and other sensory inputs that replicate an environment. A headset completely immerses the individual in the environment being generated. The most famous virtual reality tool currently is probably Oculus Rift.

The development community is looking into virtual reality for building capacity and awareness - through storytelling, simulations of alternative planning choices, facilitating dialogues with partners and clients on policy and investment choices, which can help achieve the twin goals of eradicating extreme poverty and boosting shared prosperity [4].

This type of immersive learning in the Open Learning Campus can provide learners a real opportunity to learn by doing, thereby increasing motivation and retention. It also provides a huge confidence boost to the learner, who is able to master skills in a virtual arena before applying these skills in real-world contexts. Immersive learning environments also allow learning from failures and encourage out-of-the-box thinking [5].

Virtual reality has been used in various ways in development, especially through simulations, such as the virtual reality film produced by the World Bank Group that immerses learners in the world of Syrian refugees. The United Nation's Virtual Reality Series Project created a series of virtual reality movies to address Sustainable Development Goals, giving a voice to the stories behind development challenges and Waves of Grace captures a young woman's struggle amid an Ebola epidemic after surviving a bout with the disease that stole the lives of her family.

Virtual reality is still a new field and some of its challenges are not fully understood. However, the benefits it will have on development learning cannot be overemphasized. One example is the data being generated. When Oculus Rift is used in education, using "traceability," it will be possible to know what content is most viewed, what exercises are chosen or not, which are repeated, and so on, to give timely feedback. The Open Learning Campus is planning to move forward and include the immersive learning experience to its community of learners.

The range of impact of the Open Learning Campus is wide. Beyond personal learning, the Open Learning Campus is used in policymaking as well. One example is the current opportunity to improve countries civil registration and vital statistic systems through an upcoming CRVS eLearning program with 13 modules guided by global experts [6].

Data on vital events such as births, deaths, adoptions, marriages, and divorces, crucial for planning and monitoring each country's targeted policies, programs, and services, are usually unavailable in developing countries due to deficient civil registration and vital statistics (CRVS) systems. A recent World Bank Group review [7] showed that 67 of the 230 SDG indicators, covering 12 of the 17 SDG goals, require well-functioning and multisector CRVS systems for effective monitoring. With regards to this, the CRSV course aims to train policymakers, public and civil servants, university students, researchers, development practitioners, and civil society organizations by providing practical tools and approaches to building and maintaining CRVS systems that are linked to identity management systems and tailored to local contexts. 


\section{Conclusion}

The Open Learning Campus has had over 3.8 million page views, more than 2.5 million visitors since launching in January 2016, with tens of thousands regularly enrolling for massive open online courses (MOOCs) across a wide range of subjects, including climate change, citizen engagement, and public-private partnerships. The OLC offers a catalog of over 5,000 total learning programs including policy-oriented briefs, video talks, podcasts and other on-demand resources, along with nearly 300 indepth self-paced and facilitated courses on issues related to international development. OLC currently has more than 500000 active internal and external learners and has already begun to receive industry recognition, as the recipient of a gold award for excellence in learning from Brandon Hall and other international awards and recognition.

In addition, the evaluation of the program has also been rated high with a $95.2 \%$ overall quality rating -In the survey of learners for e-courses, more than $90 \%$ gave high ratings on the overall usefulness of the courses and more than $88 \%$ gave high ratings to their knowledge and skills having increased as a result of a learning program. This was accomplished through the strong financial and technical support of OLC's partners and donors as well as the timely alignment of the World Bank Group toward knowledge and learning management and the successful integration of the Open Learning Campus in all practices and areas of the World Bank Group.

Future efforts will seek to to maintain the quality and increase the size of OLC's content while maintaining its ease of use by integrating innovative solutions, innovative pedagogical models and tools as well as innovative educational technologies to improve global scale and impact. Maintaining financial and strategic partnerships will be key to expand the Open Learning Campus program further into developing economies.

\section{References}

[1] "Open Learning Campus | World Bank Group". 2017. Olc.Worldbank.Org. http://olc.world bank.org.

[2] Jagannathan, Sheila. 2017. "A Storied Approach to Capacity Development". Blog. Blogs.worldbank.org. https://blogs.worldbank.org/publicsphere/storied-approach-capacitydevelopment.

[3] Haven, Kendall F. 2007. Story Proof: The Science Behind the Startling Power of Story. Westport, Conn.: Libraries Unlimited.

[4] Joshi-Ghani, Abha. 2014. "Scaling up Development: Learning Innovations and the Open Learning Campus". Blog. Blogs.worldbank.org. https://blogs.worldbank.org/publicsphere/ scaling-development-learning-innovations-and-open-learning-campus

[5] Jagannathan, Sheila. 2017. "Virtual Reality: The Future of Immersive Learning for Development". Blog. Blogs.worldbank.org. https://blogs.worldbank.org/publicsphere/ virtual-reality-future-immersive-learning-development.

[6] Mills, Samuel and Jagannathan, Sheila 2017. "How A New Elearning Course Will Help Improve Countries' Civil Registration and Vital Statistics Systems". Blog. 
Blogs.worldbank.org. http://blogs.worldbank.org/health/miga/how-new-elearning-coursewill-help-improve-countries-civil-registration-and-vital-statistics-systems.

[7] Mills, Samuel Lantei, Carla Abouzahr, Jane Hak Kim, Bahie M. Rassekh, and Deborah Sarpong. 2017. Civil Registration and Vital Statistics (CRVS) for Monitoring the Sustainable Development Goals (SDGS). Washington DC: The World Bank Group. http://documents.worldbank.org/curated/en/979321495190619598/Civil-registration-andvital-statistics-CRVS-for-monitoring-the-Sustainable-development-goals-SDGS.

\section{$5 \quad$ Author}

Sheila Jagannathan is the Lead Learning Specialist and Program Manager of the OLC, part of the Global Operations Knowledge Management practice of the World Bank. She serves as the organization's focal point on digital learning and issues at the intersection of technology use and education in emerging countries. She is an innovative and strategic educational leader with over 28 years' experience in designing and managing distance learning programs/knowledge products and transforming the use of online and classroom pedagogies and technology. Sheila also provides policy advice and technical assistance to World Bank country-level capacity building programs (both government and training institutes seeking to introduce technologies in their educational systems) in Asia, the Middle East and North Africa, Africa and more.

Her current areas of interest include: MOOCs, experiential pedagogy, online/hybrid strategies, development of rich multimodal learning environments, learning analytics, LMS and learning ecosystems. She serves on the advisory board and planning committees of several professional associations such as e-Learning Africa, the International Conference on e-Learning (ICEL) and the Association of Advancement of Computer Education (AACE). She holds a Masters and Certificate of Advanced Graduate Studies from Boston University in Education, Media, Technology and Artificial Intelligence-based systems for learning respectively.

This article is a revised version of a paper presented at the International Conference on E-learning in the Workplace 2017 (ICELW 2017), held in June 2017, at Columbia University in New York, NY, USA. Submitted 24 July 2017. Published as resubmitted by the author 29 August 2017. 